\title{
Etiology, Clinical Manifestation and Management of Bacterial Skin and Soft Tissue Infections Muhammad Ali' ${ }^{*}$, Shamsu I. Abdullahi', Muhammad S. Abdallah ${ }^{2}$, Lurwan Mu'azu ${ }^{3}$
}

${ }^{1}$ Department of Microbiology, Federal University Gusau, Nigeria

${ }^{2}$ Desert Research Monitoring and Control Centre, Yobe State University Damaturu, Nigeria

${ }^{3}$ Department of Biological Sciences, Federal University Gusau, Nigeria

*Corresponding Author: Muhammad Ali, Department of Microbiology, Federal University Gusau, Nigeria.

\section{Abstract}

The skin is a medium for controlled bacterial growth. It supports the growth of commensal bacteria, which protect the host from pathogenic bacteria. Environmental and local factors, host immunity, and organism adherence and virulence are intricately related to skin infection. Resident gram positive bacteria include Staphylococcus, Micrococcus, and Corynebacterium sp. Staphylococcus aureus and Streptococcus pyogenes are notoriously pathogenic in the skin. In order for bacteria to be pathogenic, they must be able to adhere to, grow on, and invade the host. The organisms possess numerous virulence genes that allow for growth in these privileged niches. Epidermal infections caused by S. aureus and S. pyogenes include impetigo and ecthyma. Dermal infections consist of erysipelas, cellulitis, and necrotizing fasciitis. The follicular infections include folliculitis, furunculosis, and carbunculosis. Moreover, S. aureus and S. pyogenes produce toxins that may elicit a superantigen response, causing massive release of cytokines. Gram-negative organisms such as Pseudomonas aeruginosa, Pasteurella multocida, Bartonella sp., Klebsiella rhinoscleromatis, and Vibrio vulnicus are not typical resident skin micro-flora but may cause cutaneous infection. Recognition of the potential for resistant pathogens causing skin and soft tissue infections (SSTIs) can assist in guiding appropriate selection of antibiotic therapy. The aim of this article is to reviews the etiology, pathogenesis, clinical manifestation, associated risk factors, and the treatment of SSTIS

Keywords: Bacteria, clinical manifestation, etiology, skin infection, soft tissue infection.

\section{INTRODUCTION}

Skin and soft tissue infections (SSTIs) involve microbial invasion ofthe skin and underlying soft tissues [1].They have variable presentations, etiologies and severities. The challenge of SSTIs is to efficiently differentiate those cases that require immediate attention and intervention, whether medical or surgical, from those that are less severe [2]. Approximately 7\% to $10 \%$ of hospitalized patients are affected by SSTIs, and they are very common in the emergency care setting. The skin has an extremely diverse ecology of organisms that may produce infection [3]. The clinical manifestations of SSTIs are the culmination of a twostep process involving invasion and the interaction of bacteria with host defences. The cardinal signs of SSTIs involve the features of inflammatory response, with other manifestations such as fever, rapid progression of lesions and bullae [1]. The diagnosis of SSTIs is difficult because they may commonly masquerade as other clinical syndromes. To improve the management of SSTIs, the development of a severity stratification approach to determine site of care and appropriate empirical treatment is advantageous. The selection of antimicrobial therapy is predicated on knowledge of the potential pathogens, the instrument of entry, disease severity and clinical complications [1].

\section{ETIOLOGY OF Skin ANd Soft Tissue INFECTIONS}

Most bacterial SSTIs are caused by gram-positive organisms, including Staphylococcus aureus, group A and B streptococci, Streptococcus viridans, and Enterococcus faecalis. Less common causes of infection 
Etiology, Clinical Manifestation and Management of Bacterial Skin and Soft Tissue Infections

include gram negative organisms such as Haemophilus influenzae, Pasteurella multocida, Capnocytophaga species, Vibrio species, Mycobacterium species, Pseudomonas species, Aeromonas species, Proteus species, Clostridium species, and other anaerobes [3]. Staphylococcus aureus is the most commonly identified infectious agent causing SSTIs. Most cases of staphylococcal SSTI are caused by community associated methicillin-resistant Staphylococcus aureus (CA-MRSA), with fewer cases attributed to healthcare associated MRSA (HA-MRSA) and methicillinsensitive Staphylococcus aureus (MSSA) [4,5]. In fact, up to three quarters of SSTIs caused by Staphylococcus aureus can be attributed to CA-MRSA strains [6]. In a study, 302 of 422 patients (76\%) presenting to the emergency department with SSTIs were infected with Staphylococcus aureus. MRSA was isolated in 249 (59\%) of these patients, MSSA in $71(17 \%)$, and other bacteria in 64 (15\%) [6]. Staphylococcus aureus is capable of secreting several toxins, which vary depending on the strain. One toxin commonly implicated as the cause of increased virulence in CAMRSA is the Panton-Valentine leukocidin (PVL) [7]. This cytotoxin causes destruction of leukocytes and tissue necrosis by inducing production of the potent chemotactic factors interleukin-8 and leukotriene B4 $[8,9]$. The role PVL plays in the pathogenesis of CAMRSA infections remains uncertain, as some studies do not show a clear linkage with increased virulence [10]. The genes lukF and lukS encode PVL [11,12]. Staphylococcus aureus also secretes enterotoxins, which are superantigens that bypass the usual immune system pathways and nonspecifically activate T cells, resulting in a massive release of cytokines. One study showed that up to half of isolates recovered from Staphylococcus aureus SSTIs produced enterotoxins [13].

Streptococcus pyogenes (also called group A streptococcus) is the streptococcal species that most commonly causes SSTIs. However, nongroup A $\beta$-hemolytic streptococci (eg, group C and $\mathrm{G}$ streptococci) have been implicated as causes of cellulitis, especially in patients with venous insufficiency [14]. Multiple virulence factors play a role in Streptococcus pyogenes disease pathogenesis [15]. The M protein, the main antiphagocytic virulence factor, inhibits activation of the alternate complement pathway, thus permitting streptococci to avoid phagocytosis and causing destruction of polymorpho nuclear leukocytes. The streptococcal pyogenic exotoxins (ie, SpeA, B, and C) act as super antigens that bind to major histocompatibility complex class 2 moleculesand T-cell receptors. This binding promotes activation of $\mathrm{T}$ cells, which in turn secrete cytokines that maycause the characteristic hypotension and multi-organfailure associated with streptococcal toxic shock syndrome [16]. Other factors that enhance streptococcal pathogenesis include surface structures, such as the hyaluronic acid capsule and fibronectin proteins (which aid in adherence, colonization, and invasion under various environmental conditions), and the enzymes hyaluronidase, streptokinase, and 4 separate types of DNases (which contribute to the microorganism's ability to disseminate through tissue planes) [15].

\section{RISK FACTORS ASSOCIATED WITH SSTIS}

The presence of specific risk factors may potentiate SSTIs, and may dictate their etiology, the course of disease and theresponse to specific treatments. The presence of risk factors for developing an SSTI has not been shown to correlate with disease severity [17]. Thus, the use of risk factors for diagnostic purposes requires further investigation. Risk factors may be organized into two categories. First, there are patientrelated factors, which may predispose to disease or have prognostic implications. Risk factors in this category include critical illness, elderly age, immunecompromised state, liver and kidney disease, and vascular (especially lymphatic or venous) insufficiency $[17,18,19]$. Because the lower leg has been shown to be the most frequent location for SSTIs, studies have described specific patient-related risk factors for such infections. A study by Björnsdóttir et al. [20] was able to quantify the likelihood of an SSTI of the lower limbs based on the presence ofStaphylococcus aureus and/or beta hemolytic streptococcus in toe webs, leg erosions or ulcers, and/or prior saphenectomy. These factors independently correlated with the development of SSTI of the lower leg. In the same population, if toe web bacteria were absent, the presence of tinea pedis had moderate predictive power for an SSTI.

Moreover, multiple patient-related risk factors may correlate to a poorer prognosis, more rapid progression of disease, slower healing and, also, more resistant pathogens. Certain risk factors (chronic renal or liver failure, asplenia, immune-compromised state, vascular insufficiency or neuropathy) should beconsidered in the determination of disease severity. 
The second category is etiological risk factors. The mechanism of injury (trauma or others) or specific exposures increases the likelihood of SSTIs caused by specific microbes Eron et al. [19].

\section{PATHOgENESIS}

Human skin serves as the first line of defence against microbial infection as a physical barrier; by secreting low $\mathrm{pH}$, sebaceous fluid and fatty acids to inhibit growth of pathogens; and by possessing its own normal flora, thus deterring colonization by other pathogenic organisms [21]. Unfortunately, having penetrated the integumentary barrier, infecting organisms may cause tissue damage and may incite an inflammatory response. Bacteria, initially in low numbers, colonize different layers of the skin architecture (ie, epidermis, dermis, subcutaneous and adipose tissues, and muscle fascia). As bacteria increase in number where the integumentary barrier is disrupted, invasion by these colonizing bacteria ensues and an SSTI develops. Involvement of pores in the epidermis may lead to folliculitis, furuncles or carbuncles. Infection of the superficial layers of skin is labeled erysipelas, whereas deeper involvement of the dermis and/ or subcutaneous tissues is labeled cellulitis. Finally, involvement of yet deeper skin structures may lead to fasciitis and even myositis. For individuals with thick adipose tissues (eg, overweight or obese individuals), involvement of fat tissue causes panniculitis [22]. The clinical presentation of most SSTIs is the culmination of a two-step process. First, invasion occurs, and then a process follows that culminates in clinical effects resulting from the interaction of the bacteria and the host defences. There are several means by which bacteria penetrate the skin barrier. The most common route is through a break in the barrier. Lacerations, bite wounds, scratches, instrumentation (eg, needles), pre-existing skin conditions, wounds (eg, chicken pox or ulcer), burns and surgery are the common mechanisms of compromising the skin barrier. These mechanisms permit the entry of normal skin flora and indigenous flora from the instrument of penetration. Other routes of penetration include contiguous spread from an adjacent infection (eg, osteomyelitis), entry of water into skin pores (eg, hottub folliculitis) and, rarely, hematogenous seeding (ie, emboli) $[18,19,23]$.

Table 1. Some SSTIS with causative organism(s) and clinical manifestations

\begin{tabular}{|c|c|c|c|c|}
\hline Infection & Site & Causative organisms & Clinical manifestation & Reference \\
\hline Impetigo & Epidermal & S. aureus, S. pyogenes & $\begin{array}{c}\text { Lesions initially begin as small vesicles } \\
\text { or pustules that rupture, forming an } \\
\text { adherent, honey-colored crust }\end{array}$ & [24] \\
\hline Ecthyma & Epidermal & S. pyogenes, Pseudomonas & $\begin{array}{l}\text { This is a deeper form of impetigo } \\
\text { in which ulcerations form beneath } \\
\text { crusted plaques }\end{array}$ & [24] \\
\hline Erysipelas & Dermal & S. pyogenes & $\begin{array}{c}\text { Characterized by acute onset of skin } \\
\text { erythema associated with fever and } \\
\text { lymphangitis }\end{array}$ & [25] \\
\hline Cellulitis & Dermal & S. pyogenes $S$. aureus, & $\begin{array}{l}\text { Rythema, edema, warmth, and } \\
\text { tenderness of the affected area. Fever, } \\
\text { tender lymphadenopathy, and abscess } \\
\text { formation }\end{array}$ & [26] \\
\hline $\begin{array}{l}\text { Necrotizing } \\
\text { fasciitis }\end{array}$ & Dermal & $\begin{array}{c}\text { S. aureus, } \\
\text { S. pyogenes, Vibrio and } \\
\text { Clostridium species }\end{array}$ & $\begin{array}{c}\text { Diffuse swelling of the affected area } \\
\text { without well-demarcated borders and } \\
\text { pain }\end{array}$ & [27] \\
\hline Folluculitis & Follicular & $\begin{array}{l}\text { S. aureus, S. pyogenes, } \\
\text { Pseudomonas and } \\
\text { Melassezia, Proteus } \\
\text { species. }\end{array}$ & $\begin{array}{l}\text { Pruritus, papules, and pustule } \\
\text { formation surrounding the hair follicle }\end{array}$ & [28] \\
\hline Carbunculosis & Follicular & S. aureus & $\begin{array}{l}\text { Associated with infection of a hair } \\
\text { follicle and extend into subcutaneous } \\
\text { tissue. They form tender and painful } \\
\text { lesion }\end{array}$ & [27] \\
\hline
\end{tabular}


Etiology, Clinical Manifestation and Management of Bacterial Skin and Soft Tissue Infections

\section{TrEatment OF SKIN AND Soft TISSUE INFECTIONS}

In addition to procedures such as incision and drainage of abscesses, antibiotic therapy is often required to eradicate SSTIs. Systemic antibiotic agents that provide coverage for both Staphylococcus aureus and Streptococcus pyogenes are most commonly used as empiric therapy for both uncomplicated and complicated deeper infections. Antibiotic resistance is a concern, given that many SSTIs are caused by MRSA and multidrug resistance is common with both CA-MRSA and HA-MRSA infections. HA-MRSA is generally susceptible to vancomycin, linezolid, and trimethoprim-sulfamethoxazole [29,30]. In contrast, CA-MRSA is usually sensitive to these antibiotics (trimethoprim-sulfamethoxazole susceptibility depending on the location) as well as a broader range of oral antimicrobial agents such as clindamycin, quinolones, and tetracycline drugs $[29,31]$. Since substantial geographic variation in antibiotic sensitivities occurs throughout the country, practitioners should familiarize themselves with the local susceptibility patterns of commonly encountered organisms [32]. The following provides an overview of the antimicrobial agents used to treat SSTIs.

\section{B-LACTAM AnTibiotic DRUgS}

Prior to the emergence of CA-MRSA, $\beta$-lactam drugs were first-line therapy for community-acquired SSTIs [33]. Empiric therapy with a $\beta$-lactam drug may no longer be sufficient for treatment now that MRSA clones are being identified more frequently as the causative agents for SSTIs. Although streptococci remain sensitive to penicillin, staphylococci are now almost universally resistant. MSSA, however, are usually sensitive to $\beta$-lactam drugs except penicillin. Physicians should be aware when treating patients who have an SSTI due to MRSA (eg, toxic shock syndrome) that cell-wall active agents such as nafcillin may cause cellular lysis with release of toxins into the bloodstream, which can upregulate the host's immune response and thereby cause a paradoxical worsening of symptoms [23]. Extended-spectrum penicillins (eg, nafcillin, dicloxacillin) or firstgeneration cephalosporins (eg, cephalexin, cefazolin), with or without the addition of an antibiotic that stops toxin production (eg, clindamycin), are examples of $\beta$-lactam drugs that are effective against MSSA and streptococci [34].
Clindamycin is an important adjunct to therapy for SSTIs because of its ability to suppress bacterial toxin production, including streptococcal pyrogenic exotoxin A, PVL, and staphylococcal enterotoxin B. However, MRSA may become resistant to clindamycin upon exposure to this drug via an inducible erm gene found in certain strains. The microbiology laboratory usually performs a disk diffusion test, known as a D-test, to determine if inducible resistance is present. The test is completed by placing a clindamycin antibiotic disk approximately $2 \mathrm{~cm}$ away from an erythromycin antibiotic disk on growth medium containing colonies of Staphylococcus aureus. If inducible resistance is present, there will be an abrupt flattening of the clindamycin zone of inhibition in the area between the 2 disks reflecting the growth of bacteria within the clindamycin diffusion zone. The area around the clindamycin disk resembles the letter D (hence, the name of the technique) [33].

\section{LINEZOLID}

Much like clindamycin, linezolid suppresses bacterial toxin production and has a long post antibiotic effect [35]. It is approved for the treatment of uncomplicated and complicated SSTI caused by Staphylococcus aureus and streptococci based on data from clinical trials comparing it to the $\beta$-lactam antibiotic drugs [36,37]. This antimicrobial agent is bacteriostatic to Staphylococcus aureus and enterococcus strains, with some bactericidal activity against streptococci [17]. Linezolid may be used as an alternative agent for the treatment of SSTI in patients with a confirmed penicillin allergy [37].

\section{FLUOROQUINOLONES}

In general, Streptococcus pyogenes infection is susceptible to fluoroquinolones. However, there is geographic variability in susceptibilities, with up to $80 \%$ of CA-MRSA isolates showing resistance at some institutions [6]. With the increased use of this class of antibiotics, resistance to fluoroquinolones also has been increasing [38]. Care must be exercised when prescribing fluoroquinolones (eg, ciprofloxacin, levofloxacin) without the appropriate culture data.

\section{OTHER AgEnts}

Vancomycin is an intravenous agent that can be administered to patients with SSTIs who have 
allergies against $\beta$-lactam agents [23]; it is effective against both CA-MRSA and HA-MRSA strains [29]. Retrospective studies and case reports indicate that sulfa and tetracycline drugs may be efficacious in treating SSTIs due to MRSA [39]. Sensitivities to sulfa and tetracycline drugs vary from region to region, and patients previously exposed to certain classes of medications (eg, sulfa prophylaxis for prevention of Pneumocystis jiroveci pneumonia) may show increased rates of treatment failures [29,31]. However, more head-to-head studies of the older antimicrobial agents are needed to better delineate their roles in treatment regimens. Newer antimicrobial agents, such as daptomycin and tigecycline, are also approved for the treatment of SSTIs. Daptomycin is a lipopeptide that is only active against gram-positive organisms such as staphylococci (including MRSA strains) and streptococci [40]. Tigecycline is structurally related to tetracycline. It is thought to have a broadspectrum activity with bacteriostatic in vitro activity against many gram-positive and gram-negative organisms, including MRSA and vancomycin-resistant enterococci; it is not effective against Pseudomonas aeruginosa [41].

\section{TREATMENT DURATION}

Short-course therapy for an uncomplicated SSTI is the standard of care. Treatment duration depends largely on patient response and extent of infection. In a study that compared a 5-day course of fluoroquinolone therapy with a 10-day course of levofloxacin for the treatment of uncomplicated cellulitis, the outcomes were similar in both groups, with $98 \%$ of patients in each treatment arm achieving clinical resolution [42]. In a separate study of 492 patients who had various SSTIs due to CA-MRSA, antibiotic treatment with a median duration of 10 days resulted in the best outcomes, although patients received between 7 and 14 days of medication $[43,44]$. On average, treatment for most lesions requires 10 to 14 days of antibiotic therapy. It should be noted that following initiation of antibiotic treatment, if there this no response in five days, this should prompt a change in the antibiotic regimen or other investigations to verify the diagnosis [45].

\section{ConCLUSiON}

Bacterial skin infections have a variety of presentations from localized, trivial infection to rapidly progressive infection with systemic toxicity and considerable mortality. It is important for physicians to have a working knowledge of the local antimicrobial susceptibilities to avoid treatment failures and to prevent inappropriate antibiotic usage.

\section{REFERENCES}

[1] Chiller K, Bryan A. Selkin and Murakawa GJ. Skin Microflora and Bacterial Infections of the Skin. 22001; Vol. 6 (3), 170-174

[2] Stevens DL, Bisno AL, Chambers HF, et al; Infectious Diseases Society of America. Practice guidelines for the diagnosis and management of skin and soft-tissue infections. Clin Infect Dis 2005;41:1373-406

[3] V Ki, C Rotstein. Bacterial skin and soft tissue infections in adults: A review of their epidemiology, pathogenesis, diagnosis, treatment and site of care. Can J Infect Dis Med Microbiol 2008;19(2):173-184.

[4] Skiest DJ, Brown K, Cooper TW, et al. Prospective comparison of methicillin susceptible and methicillin-resistant community-associated Staphylococcus aureus infections in hospitalized patients. J Infect 2007;54:427-34.

[5] Popovich KJ, Weinstein RA, Hota B. Are community-associated methicillin resistant Staphylococcus aureus (MRSA) strains replacing traditional nosocomial MRSA strains? Clin Infect Dis 2008;46:787-94.

[6] Moran GJ, Krishnadasan A, Gorwitz RJ, et al; Emergency ID Net Study Group. Methicillinresistant Staphylococcus aureus infections among patients in the emergency department. N Engl J Med 2006;355:666-74.

[7] Naimi TS, LeDell KH, Como-Sabetti K, et al. Comparison of community and health careassociated methicillin-resistant Staphylococcus aureus infection. JAMA 2003;290:2976-84.

[8] Genestier AL, Michallet MC, Prévost G, et al. Staphylococcus aureus Panton-Valentine leukocidin directly targets mitochondria and induces Baxindependent apoptosis of human neutrophils. J Clin Invest 2005;115:3117-27.

[9] König B, Prévost G, Piémont Y, König W. Effects of Staphylococcus aureus leukocidins on inflammatory mediator release from human granulocytes. J Infect Dis 1995;171:607-13. 
Etiology, Clinical Manifestation and Management of Bacterial Skin and Soft Tissue Infections

[10] Voyich JM, Otto M, Mathema B, et al. Is PantonValentine leukocidin the major virulence determinant in community-associated methicillin-resistant Staphylococcus aureus disease? J Infect Dis 2006;194:1761-70.

[11] Diep BA, Sensabaugh GF, Somboona NS, et al. Widespread skin and soft tissue infections due to two methicillin-resistant Staphylococcus aureus strains harboring the genes for Panton-Valentine leukocidin. J ClinMicrobiol 2004; 42:2080-4.

[12] Said-Salim B, Mathema B, Braughton K, et al. Differential distribution and expression of Panton-Valentine leukocidin among communityacquired methicillin-resistant Staphylococcus aureus strains. J ClinMicrobiol 2005;43:3373-9.

[13] Naidu S, Rao PN, Rajyalakshmi K, Naidu AS. Incidence of enterotoxin producing Staphylococcus aureus among pyogenic skin infections. J HygEpidemiolMicrobiolImmunol 1989;33:277-82.

[14] Baddour LM, Bisno AL. Non-group A betahemolytic streptococcal cellulitis. Association with venous and lymphatic compromise. Am J Med 1985;79: 155-9.

[15] Bisno AL, Brito MO, Collins CM. Molecular basis of group A streptococcal virulence. Lancet Infect Dis 2003;3:191-200.

[16] Bisno AL, Stevens DL. Streptococcal infections of skin and soft tissues. $\mathrm{N}$ Engl J Med 1996;334:240-5.

[17] Baddour LM. Recent considerations in recurrent cellulitis.Curr Infect Dis Rep 2001;3:461-5.

[18] Swartz MN. Clinical practice.Cellulitis. N Engl J Med2004;350:904-12.

[19] Eron LJ, Lipsky BA, Low DE, Nathwani D, Tice $\mathrm{AD}$, Volturo GA; Expert panel on managing skin and soft tissue infections. Managing skin and soft tissue infections: Expert panel recommendations on key decision points. J AntimicrobChemother 2003;52:i3-17.

[20] Björnsdóttir S, Gottfredsson M, Thórisdóttir AS, et al. Risk factors for acute cellulitis of the lower limb: A prospective case-control study. Clin Infect Dis 2005;41:1416-22.
[21] McAdam AJ, Sharpe AH.Infectious diseases bacterial infections. In: Kumar V, Abbas AK, Fausto N, eds. Robbins \&Cotran Pathologic Basis of Disease. Philadelphia: Elsevier Inc, 2005:371-96.

[22] Nauta RJ. A radical approach to bacterial panniculitis of the abdominal wall in the morbidly obese. Surgery 1990;107:134-9.

[23] Stevens DL, Bisno AL, Chambers HF, et al; Infectious Diseases Society of America. Practice guidelines for the diagnosis and management of skin and soft-tissue infections [published errata appear in Clin Infect Dis 2005;41:1830 and 2006;42:1219]. Clin Infect Dis 2005;41:1373-406.

[24] Schachner LA. Treatment of uncomplicated skin and skin infections in the pediatric and adolescent patient populations. J Drugs Dermatol 2005;4:s30-s33.

[25] Bonnetblanc JM, Bedane C. Erysipelas: recognition and management. Am J ClinDermatol 2003;4:157-63.

[26] Lazzarini L, Conti E, Tositti G, De Lalla F. Erysipelas and cellulitis: clinical and microbiological spectrum in an Italian tertiary care hospital. J Infect 2005;51:383-9.

[27] Sukumaran V and Senanayake S. Bacterial skin and soft tissue infections Aust Prescr 2016;39:159-63 http://dx.doi.org/10.18773/ austprescr.2016.058

[28] Luelmo-Aguilar J, Santandreu MS. Folliculitis: recognition and management. Am J ClinDermatol 2004;5:301-10.

[29] Naimi TS, LeDell KH, Como-Sabetti K, et al. Comparison of community and health careassociated methicillin-resistant Staphylococcus aureus infection. JAMA 2003;290:2976-84.

[30] Weigelt J, Itani K, Stevens D, et al. Linezolid versus vancomycin in treatment of complicated skin and soft tissue infections. Antimicrob Agents Chemother 2005;49:2260-6.

[31] Ruhe JJ, Menon A. Tetracyclines as an oral treatment option for patients with communityonset methicillin-resistant Staphylococcus aureus skin and soft tissue infections. Antimicrob Agents Chemother 2007;51:3298-303. 
[32] Kuehnert MJ, Hill HA, Kupronis BA, et al. Methicillin-resistant-Staphylococcus aureus hospitalizations, United States. Emerg Infect Dis 2005;11:868-72.

[33] Lewis JS and Jorgensen JH. Inducible resistance in staphylococci: should clinicians and microbiologists be concerned? Clin Infect Dis 2005;40:280-5.

[34] Frazee BW, Lynn J, Charlebois ED, et al. High prevalence of methicillin resistant Staphylococcus aureus in emergency department skin and soft tissue infections. Ann Emerg Med 2005;45:311-22.

[35] Coyle EA, Cha R, Rybak MJ. Influences of linezolid, penicillin, and clindamycin, alone and in combination, on streptococcal pyrogenic exotoxin A release. Antimicrob Agents Chemother 2003;47:1752-5.

[36] 36. Wise R, Andrews JM, Boswell FJ, Ashby JP. The in-vitro activity of linezolid (U-100766) and tentative breakpoints. J Antimicrob Chemother 1998;42:721-8.

[37] Stevens DL, Smith LG, Bruss JB, et al. Randomized comparison of linezolid (PNU-100766) versus oxacillin-dicloxacillin for treatment of complicated skin and soft tissue infections. Antimicrob Agents Chemother 2000;44:3408-13.

[38] Duesberg CB, Malhotra-Kumar S, Goossens H, et al. Interspecies recombination occurs frequently in quinolone resistance-determining regions of clinical isolates of Streptococcus pyogenes. Antimicrob Agents Chemother 2008;52:4191-3.
[39] Cenizal MJ, Skiest D, Luber S, et al. Prospective randomized trial of empiric therapy with trimethoprim-sulfamethoxazole or doxycycline for outpatient skin and soft tissue infections in an area of high prevalance of methicillin resistant Staphylococcus aureus. Antimicrob Agents Chemother 2007;51:2628-30.

[40] Steenbergen JN, Alder J, Thorne GM, Tally FP. Daptomycin: a lipopeptide antibiotic for the treatment of serious gram-positive infections. J Antimicrob Chemother 2005;55:283-8.

[41] Pankey GA. Tigecycline. J Antimicrob Chemother 2005;56:470-80.

[42] Hepburn MJ, Dooley DP, Skidmore PJ, et al. Comparison of short-course (5 days) and standard (10 days) treatment for uncomplicated cellulitis. Arch Intern Med 2004;164:1669-74.

[43] Ruhe JJ, Smith N, Bradsher RW, Menon A. Community-onset methicillin resistant Staphylococcus aureus skin and soft-tissue infections: impact of antimicrobial therapy on outcome. Clin Infect Dis 2007;44:777-84.

[44] Abrahamian FM, Talan DA, Moran GJ. Management of skin and soft tissue infections in the emergency department. Infect Dis Clin North Am 2008;22:89-116.

[45] Barton M, Hawkes M, Moore D, etal. Guidelines for the prevention and management of communityassociated methicillin resistant Staphylococcus aureus: A perspective for Canadian health care practitioners. Can J Infect Dis Med Microbiol 2006;17(Suppl):1B-24B.

Citation: Muhammad Ali, Shamsu I. Abdullahi et al. Etiology, Clinical Manifestation and Management of Bacterial Skin and Soft Tissue Infections. Archives of Dermatology and Skin Care. 2020; 3(1): 10-16

Copyright: (C) 2020 Muhammad Ali, Shamsu I. Abdullahi et al.. This is an open access article distributed under the Creative Commons Attribution License, which permits unrestricted use, distribution, and reproduction in any medium, provided the original work is properly cited. 